\title{
The Work Experience Survey: An on-the-job needs assessment tool to promote successful career outcomes for young adult central nervous system cancer survivors
}

\author{
David R. Strauser ${ }^{\mathrm{a}, \mathrm{e}, *}$, Stuart P. Rumrill ${ }^{\mathrm{b}}$, Phillip D. Rumrill, Jr ${ }^{\mathrm{c}}$, \\ Chelsea E. Greco a and Stacia Wagner ${ }^{\mathrm{d}}$ \\ ${ }^{a}$ University of Illinois at Urbana-Champaign, Champaign, IL, USA \\ ${ }^{\mathrm{b}}$ University of Wisconsin-Madison, Madison, WI, USA \\ ${ }^{\mathrm{c}}$ University of Kentucky, Human Development Institute and Rehabilitation Counseling Program, \\ Lexington, KY, USA \\ ${ }^{\mathrm{d}}$ Children's Brain Tumor Foundation, New York, NY, USA \\ ${ }^{\mathrm{e}}$ National Changhua University of Education, Changhua City, Taiwan
}

Revised/Accepted August 2019

\begin{abstract}
.
PURPOSE: Four employed young adults who survived brain cancer participated in an evaluation of barriers to their continued employment and career development.

METHOD: A trained interviewer completed the Work Experience Survey (WES) in teleconsultation sessions with each participant to identify his or her: (a) barriers to worksite accessibility, (b) difficulties performing essential functions of his or her job, (c) concerns regarding job mastery, and (d) extent of job satisfaction.

RESULTS: Resulting largely from the medical and psychosocial sequelae of their illnesses (especially cognitive and mobility impairments), participants reported a wide range of difficulties in performing essential functions of their jobs (5 to 19) that have the potential to significantly affect their productivity. Job mastery problems reflected outcomes associated with cancer such as 'believing that others think I do a good job' and 'having the resources (e.g., knowledge, tools, supplies, and equipment) needed to do the job.' Other job mastery concerns reflected idiosyncratic aspects of a specific job setting such as 'being able to speak with my supervisor about promotion.'

CONCLUSIONS: Although all four participants expressed a strong desire to continue and advance in their careers, they reported significant barriers to job satisfaction that must be addressed in order for that to happen. The interviewer concluded the WES interview by recommending a job accommodation plan, which included suggestions from Job Accommodation Network (JAN) consultants.

IMPLICATIONS: The WES can be used in psychosocial treatment planning to offer guidelines for young adult CNS survivors to follow in requesting job modifications and assistive technology to improve career development and employment outcomes.
\end{abstract}

Keywords: Work Experience Survey, young adults, brain cancer

\footnotetext{
*Address for correspondence: David Strauser, Ph.D., University of Illinois at Urbana-Champaign, 213A Huff Hall, 1206 South
} 


\section{Introduction}

Research has consistently found that, although a majority of child cancer survivors do not suffer from severe psychological distress and positively acclimate into adulthood (Michel et al., 2010; Zeltzer et al., 2009), there is a significant group that experiences lasting medical concerns that have a substantial impact on the achievement of crucial social roles such as employment. Engaging in productive and appropriate career development activities leads to participating in meaningful employment, which is related to increased quality of life, higher levels of independence, self-esteem, and positive family and social relationships. Numerous studies with young adults have identified decreased career development and unemployment as a serious issue facing survivors of childhood cancer. Results from a study using data from the Childhood Cancer Survivor Study (CCSS) found that survivors with poor physical health were eight times more likely to be unemployed when compared to healthy survivors and that survivors viewed health related concerns as a significant barrier to employment (Kirchoff et al., 2010, 2011). Being diagnosed with a chronic medical condition is related to increased risk of experiencing unemployment and dysfunctional career development (Strauser et al., 2012). This finding is important for childhood cancer survivors given that $73.5 \%$ of the survivors in the CCSS study reported at least one chronic medical condition 30 years post cancer diagnosis (Oeffinger et al., 2006). The potential implications of secondary chronic health conditions to the career development process are notable and contribute to decreased employment, financial security, and independence. The impact of decreased physical health on employment has also been demonstrated in the St. Jude Lifetime Cohort Study, with physically healthy survivors reporting higher levels of emotional functioning and higher levels of vocational identity and career readiness (Strauser et al., 2014). Findings from that study suggest that the vocational success of childhood cancer survivors is related to the long-term physical effects associated with cancer treatment.

Research with childhood cancer survivors has also found that certain types of childhood cancer are related to increased risk for poor adjustment and maladaptation. Individuals treated for central nervous system tumors have been found to have increased levels of psychological distress, poor functional outcomes and lower overall quality of life (Meyer \&
Kieran, 2002; Recklitis et al., 2010). The intrusive nature of the treatment and toxicity of the therapies directed to the brain leads to depreciated physical functioning, overall health, learning, socialization, and psychological well-being. Studies examining the overall psychological adjustment of pediatric brain tumor survivors have found an increased vulnerability to depression and social withdrawal (Fossen et al., 1998; Glaser et al., 1997; Mulhern et al., 1993; Seaver et al., 1994) and decreased social competency (Carey et al., 2001; Ness et al., 2005; Vannatta et al., 1998). Survivors of pediatric brain tumors have been found to be at high risk for not attaining developmental milestones associated with positive peer relationships and productive career and employment outcomes (Gurney et al., 2009; Maurice-Stam et al., 2007). According to a study using the CCSS data, of the 1,101 adult survivors of pediatric brain tumors, $26 \%$ were unemployed, $74 \%$ were unmarried, and $28 \%$ had incomes of less than $\$ 20,000$ per year (de Boer et al., 2006). These findings are consistent with a metanalysis investigating childhood cancer survivors and unemployment (Mostow et al., 1991) where survivors of childhood cancer in general were twice as likely to be unemployed when compared to healthy controls, survivors of pediatric brain tumors reported a 5-fold risk of being unemployed. In a study of 342 survivors of pediatric brain tumors and matched sibling controls, survivors were 11 times more likely to report being unemployed compared to their sibling controls. Issues related to late effects such as increased visual and hearing problems, fatigue, decreased emotional functioning, and having radiation therapy have been identified as health conditions that negatively impact the survivor's ability to meet the demands of competitive employment and the ability to obtain and maintain meaningful work (Henrichs \& Schmale, 1993). Childhood brain tumor survivors have also been found to be 30 times less likely to drive than sibling controls, potentially contributing to the high rates of unemployment. With the sense of self-identity and competence being directly tied to success in one's work, an inability to obtain employment can have a negative impact on quality of life and sense of self (Strauser et al., 2015). Finally, ssurvivors of pediatric brain tumors have been identified as having low levels of career readiness, work personality (Strauser et al., 2012) and underdeveloped vocational identities (Judge et al., 2003), with treatment intensity, age at diagnosis, and physical health indirectly affecting career readiness via impact on emotional functioning and vocational identity (Strauser et al., 2014). 
Because of the significant difficulties noted with the career development process and decreased employment outcomes for survivors of childhood brain tumors, recent research has attempted to develop an increased understanding of the factors associated with the challenges experienced by pediatric brain tumor survivors related to career development and employment. The Illinois Work and Wellbeing Model $\left(\mathrm{IW}^{2} \mathrm{M}\right)$ has recently been identified as a model that can be used in conceptualizing factors related to career development and employment of young adult cancer survivors (Strauser et al., 2013). The conceptual framework was informed by the International Classification of Functioning (ICF) Model as well as theory based research regarding employment of individuals with chronic health conditions. The model is comprised of three major domains (Contextual, Career/Employment Development, and Participation) that have a bidirectional relationship that informs outcomes and potential interventions. This model provides a structured framework to conceptualize factors that impact the career development for young adult survivors of pediatric CNS tumors and has the potential to guide career development and employment research and service in the cancer population (Fig. 1.)

Utilizing a vocational counseling framework, such as the Illinois Work and Wellbeing model, researchers have begun to identify potential areas in which survivors of pediatric brain tumors can be categorized to better explain the challenges experienced around finding and maintaining employment and identify potential interventions that can be directed at improving the relationship between the Contextual and Career/Employment domains. One area of intervention that has been found to be robust within the broader disability community is being provided access to appropriate career and job related accomodations. Despite the success of appropriate job accommodations in improving employment outcomes within the broader disability community, no work has been done to examine the potential effect or utilization of job accommodations within the childhood brain tumor survivor community on career and employment outcomes. As a result, there would appear to be a significant need to address this issue and start to examine the potential application of job accommodations within this population.

\subsection{The Work Experience Survey}

The Work Experience Survey (WES; Roessler et al., 1995) was designed to assess person-insituation compatibility, specifically employee and job compatibility, in relation to barriers to worksite accessibility, barriers to performance of essential job functions, job mastery concerns, and job satisfaction ratings. Developed in research with adults with multiple sclerosis, arthritis, and traumatic brain injury (Allaire et al., 2003; Roessler et al., 1995), the WES assessment concludes with the development of a job accommodation plan drawing on knowledge of the employee, employer, rehabilitation professional, and information from resources such as the Job Accommodation Network (JAN; Ruh et al., 2009). The employee, employer, and rehabilitation professional should evaluate these accommodation strategies to determine the extent to which they restore the compatible relationship between worker and job and are perceived by the employer as practical and cost effective. When these conditions are met, cancer survivors experience an increased probability of

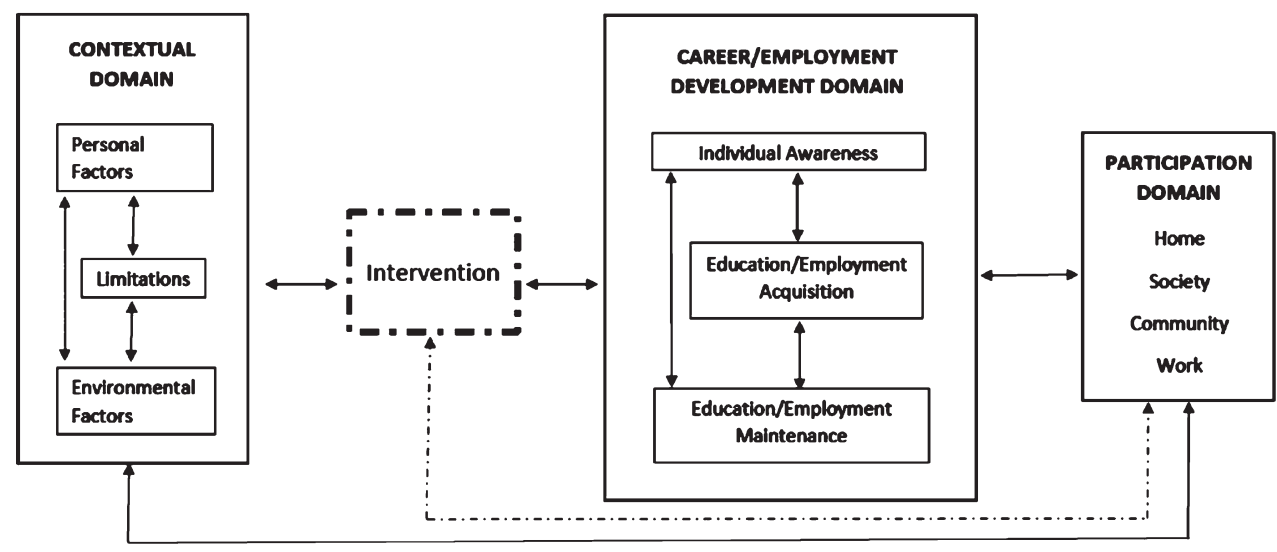

Fig. 1. Illinois Work and Wellbeing Model $\left(\mathrm{IW}^{2} \mathrm{M}\right)$. 
retaining satisfying employment, a meaningful adult role fundamental to one's sense of personal identity (Cotton, 2012; Strauser, 2013). Empirical findings regarding the significant relationship between number of worksite accessibility and essential function barriers and extent of job satisfaction support the importance of a rehabilitation intervention based on results from a job/person contextual assessment such as the WES (Rumrill et al., 2004).

\subsection{Purpose}

The purpose of this study was to demonstrate the application of this person-in-situation or contextual assessment of job/person compatibility in the case of four employed young adults who had survived childhood brain cancer. The jobs held by participants in this study represented are early positions in what would ideally be a sustained career trajectory. Success or failure at this juncture in their careers would have significant implications for their long-term ability to manage personal careers while coping with the effects of cancer, hence the need to adopt a holistic and contextual perspective on barriers to workplace accessibility and performance of essential functions and the accommodation plans needed to reduce or remove these barriers.

\section{Method}

Applying purposive sampling techniques from the qualitative research paradigm (Rumrill \& Bellini, 2018), the authors selected the four participants for this study to represent a range of career fields and job duties. The sample was limited to four participants to enable an in-depth description of each participant's job retention profile (see Results section).

\subsection{Participants}

Ranging in age from 26 to 32 years, this study's sample included two males and two females. Two participants identified their race/ethnicity as Caucasian, one participant identified as Asian, and one participant chose not to report a racial/ethnic identity. Three participants were employed part-time at the time of the investigation and one was employed full-time. The job titles reported by participants in this study were temporary administrative clerk at a college, retail team member, cashier/customer service representative, and fellowship lawyer. Participants had been coping with the sequelae of their brain tumors for eleven to twenty years at the time of this investigation.

\subsection{Instrumentation}

In one telephone interview with the interviewer, each participant completed the six sections of the WES: background information, barriers to worksite accessibility, barriers to performance of essential job functions, job mastery concerns, job satisfaction ratings, and job accommodation plan (top priority barriers and feasible solutions; Roessler et al., 1995). In responding to the section on worksite accessibility, participants indicated whether they encountered any barriers created by public walks, parking lots, steps, and elevators. The essential functions section included job functions or conditions in six areas: physical abilities, cognitive abilities, taskrelated abilities, social abilities, working conditions, and company policies. An abbreviated version of the Career Mastery Inventory (adapted with permission; Crites, 1990), the self-report measure of job mastery consisted of 24 items addressing six areas of career mastery: getting the job done, fitting into the workplace, learning the ropes, getting along with others, getting ahead, and planning the next career step. Previous research supports the internal consistency of the job mastery scale (Cronbach's Alpha $=.78$; Rumrill et al., 2004). The job satisfaction rating scale presents 20 work reinforcers from the Minnesota Theory of Work Adjustment (Swanson \& Schneider, 20130. With respect to their current employment experiences, participants used a three-point scale to indicate whether their access to a specific reinforcer was: (a) too little, (b) about right, or (c) too much. In previous research (Rumrill et al., 2004), the internal consistency reliability (i.e., Cronbach's Alpha) of the job satisfaction scale was .91.

\subsection{Procedure}

Each WES telephone interview (one per participant) required 30-90 minutes to complete, and they were all conducted by the same interviewer. Based on the original plan developed at the end of the WES interview and information from the JAN website, the interviewer provided each participant with an accommodation plan. The participant and interviewer decided on a final accommodation approach, and the interviewer suggested strategies for participants to use in requesting needed accommodations from their employers (Roessler \& Rumrill, 2015). 
Where feasible, these accommodations were implemented in the job setting and monitored to determine the extent to which they improved the individuals' job performance and satisfaction.

\section{Results}

The following case studies describe results from WES interviews with four employed young adult brain cancer survivors. The intent is to illustrate how health and rehabilitation professionals can use the WES as a post-employment needs assessment strategy.

\subsection{Case \#1}

The first case is that of a 26-year old Asian American male who acquired a brain tumor at age 15 . His highest educational degree being his high school diploma, he is currently working part time as a temporary employee at a public university in the northeastern region of the United States. Specifically, this participant's job entails clerical duties such as operating computers and data entry, answering the telephone, filing and shredding documents, and maintaining a clean office. When asked what symptoms associated with brain cancer pose functional limitations at work, this participant noted issues with fatigue and muscle weakness, short-term memory, following specific directions, and coping with stress.

\subsubsection{Accessibility and essential functions}

This participant reported that his workplace is entirely accessible, and did not report any barriers in this section of the WES. With respect to performance of essential job functions, this participant mentioned a total of 7 problems - immediate memory, short-term memory, long-term memory, work pace/sequencing, performing under stress/deadlines, remembering, and working around others.

\subsubsection{Job mastery}

In the job mastery section, the participant noted only two concerns. He identified "believing that others think I do a good job" and "willing to make changes when necessary" as impediments to full mastery of his position.

\subsubsection{Job satisfaction}

Generally satisfied with his position, this participant identified only two work reinforcers as problematic. He expressed dissatisfaction with hav- ing enough opportunity for advancement (too little), and being busy all of the time (too little).

\subsubsection{Employee-identified accommodations}

As noted in the Method section, the WES asks participants to suggest reasonable accommodations for their most prominent career maintenance barriers and identify resources that could assist them in implementing those solutions. This participant copes with his short-term memory issues by making sure to write things down and by asking his supervisor for additional instructions or clarification if he needs help remembering steps to complete a task. In the Job Satisfaction category, the participant reported that he often feels dissatisfaction in being not busy enough on the job. However, he also explained that, oftentimes when he is assigned tasks, it can be too much of a workload all at once and the deadlines can evoke stress and anxiety. To cope with this, the participant suggested that he could utilize effective communication skills with his supervisor and possibly ask for more flexibility with deadlines and priority-setting.

\subsubsection{Accommodation strategies suggested by the Job Accommodation Network}

After completing the WES interview with this participant, the interviewer contacted the Job Accommodation Network (JAN) and visited the JAN website for additional recommendations to address the participant's highest-priority job retention barriers. JAN consultants suggested the following strategies that the participant's employer could implement to help this individual with short term memory issues at work:

- provide and allow the use of memory "apps" from the Google Play and iTunes store

- provide additional training time/training refreshers

- provide electronic organizers

- allow a support person such as a job coach

- provide the employee with clear, detailed written instructions

To alleviate this participant's stated difficulties with work sequencing being too fast and performing under stress/deadlines, JAN consultants recommended the following as possible accommodation choices:

- "apps" to help manage time

- a "color coded" system-color coordination applied to office products and files to help with organization and time management 
- timers and watches

- wall calendars and/or planning apps

- provide the employee with clear, detailed written instructions

- "apps" for stress and anxiety

- counseling/therapy-the employer may need to consider flexibility in work hours so the employee can attend counseling

- environmental sound machines/sound conditioners to help block out extraneous noise that may be distracting

- flexible schedules/the employer may allow periods of mental rest

- job restructuring/reallocating or redistributing marginal functions of the job

\subsection{Case \#2}

The second case study involves a 26-year old Caucasian female who acquired brain cancer at age 6 . This participant holds a bachelor's degree in Sociology with a minor in Psychology, and she is currently working on a part-time basis at a grocery store where her job primarily involves cleaning, stocking products, assisting customers in finding items in the store, and filling bags at check-out. When asked what effects of her brain tumor impinge (or have impinged) upon her job performance, she identified loss of control on the right side of her body, balance, muscles moving involuntarily, lack of right peripheral vision, memory issues and slower thought processing.

\subsubsection{Accessibility and essential functions}

The participant conveyed that despite her balance and motor issues, this particular workplace is totally accessible and did not indicate any problems getting to, from, or around the workplace on any of the items on the accessibility section of the WES. For essential job functions, the participant checked six conditions that pose problems - some kneeling, using right hand, using right leg, short-term memory, long-term memory, and working alone.

\subsubsection{Job mastery and job satisfaction}

In the job mastery section, the participant noted eight concerns reflecting her uncertainty about getting the job done, fitting into the workforce, learning the ropes, getting ahead, and planning the next career step. These concerns were: having what I need to do my job (knowledge, tools, supplies, equipment); working mostly because I like my job; knowing who to go to if I need help; understanding company rules and regulations; knowing my way around work; having a plan for where I want to be in my job in the future; understanding what I have to do to get promoted; and considering what I will do in the future. Of the 20 work reinforcers in the job satisfaction scale, participant \#2 noted three sources of dissatisfactionthe job giving her a feeling of accomplishment (too little), being busy all the time (too little), and getting recognition for the work she does (too little).

\subsubsection{Employee-identified accommodations}

In the accommodation plan section of the WES, this participant identified notetaking and writing things down as solutions to help with her shortterm memory issues. The participant suggested that she could reach out to co-workers to ask them to write tasks down for her so she has instructions that are readily available, and she recommended asking them to verbally repeat instructions if necessary. With respect to her difficulties in kneeling when asked to stock certain items in the store or clean, this participant described communicating more frequently and openly with her employers, asking for alternative tasks or assistance if she encounters problems.

\subsubsection{Accommodation strategies suggested by the Job Accommodation Network}

Similar to the accommodations suggested for Participant \#1, JAN consultants recommended the following strategies to help this participant compensate for her short-term memory difficulties:

- provide and allow the use of memory "apps" from the Google Play and iTunes store

- provide additional training time/training refreshers

- provide electronic organizers

- support person such as a job coach

- provide the employee with clear, detailed written instructions

- allow the employee to audio-record meetings

- provide written as well as verbal instructions

- allow additional training time

- provide written checklists and use color-coding to help identify items

- post instructions close to frequently used equipment

In terms of difficulties that this participant experiences with job tasks which require kneeling, JAN consultants offered the following as reasonable accommodation possibilities: 
- low positioned stools

- low task chairs (stools on wheels)

- job restructuring

- installation of grab bars (rails and bars installed into walls or from floors to help prevent falls and enhance coordination)

\subsection{Case \#3}

The third participant is a 32-year old Caucasian male who developed brain cancer at the age of 15 . He holds an associate's degree in creative writing and is pursuing a bachelor's degree in media communications. He works part-time at a retail store where his responsibilities include stocking shelves, cleaning, maintaining inventory in the store, cashiering, and general customer service including helping customers find items in the store and answering the telephones. This is a temporary, part-time job for this participant, and he relayed that he has never held a full-time job but rather has "bounced around" (his words) different retail customer service positions. He identified problems with muscle strength, fatigue, balance, hearing, memory, depression, and anxiety the latter especially in regard to excessive noise, large crowds, and social gatherings.

\subsubsection{Accessibility and essential functions}

This participant identified only two accessibility barriers at his worksite- the entrance of the facility (due to steps) and lighting (often being too bright or too dim). As for essential functions, he mentioned several present concerns. These related to physical abilities (standing all day, walking for 8 hours, some kneeling, some stooping, some climbing, hearing well, and lifting over 25 pounds), cognitive abilities (immediate memory, short-term memory, long-term memory, thought processing, reasoning, and problem solving), task-related abilities (little feedback on performance, following specific instructions, and remembering), and company policies (no accrual of sick leave, no "comp" time, vague job descriptions, and rigid sick/vacation leave policies).

\subsubsection{Job mastery and satisfaction}

This participant reported several concerns in the job mastery section: "believing that others think I do a good job;" "understanding how my job fits into the "big picture';" "knowing who to go to if I need help;" "understanding company rules and regulations;" "having a plan for where I want to be in my job in the future," "talking with supervisor about what
I need to do to get promoted;" and "having a good idea of how to advance in this company." He also identified multiple work reinforcers as areas of concern. Specifically, he cited feeling "too little" satisfaction in response to the following statements: "I do things that make use of my abilities;" "this job gives me a feeling of accomplishment;" "I am busy all of the time;" "I do something different every day;", "my pay compares well with that of other workers;" "the job provides for steady employment;" "the job has good working conditions;" "the job provides an opportunity for advancement;" "I get recognition for the work I do;" "I tell people what I do;" "I am "somebody' in the community;" "my boss backs up the workers with top management;" "my boss trains the workers well;", "I try out some of my ideas;" and "I make decisions on my own."

\subsubsection{Employee-identified accommodations}

The third participant generated several possible solutions to his on-the-job barriers. One of this participant's biggest barriers was issues with management. He reported that he constantly feels undermined by his employer and that he is frequently demoted to tasks with less responsibility. He also noted that his hours are frequently cut. He felt that he is not being heard and respected, and that management is not giving him an opportunity to take on new responsibilities and demonstrate/exercise his skills. To combat this, the participant said that he could utilize more open communication and be more assertive and firm in talking with his supervisor. If he happens to be unsuccessful, he suggested he may be able to reach out to state Vocational Rehabilitation (VR) services, a human resources representative, or the agency (the U.S. Equal Employment Opportunity Commission [EEOC]) that enforces the Americans with Disabilities Act. In regard to his physical limitations - muscle strength, fatigue, balance issues, etc. - this participant believed that accommodations such as the option to sit in a chair or having permission to take more frequent breaks would be very beneficial. Again, this would first involve open communication with his supervisor, followed by moving up the chain of command if he runs into difficulties with communicating his concerns and reaching a solution with his supervisor. The last significant barriers this participant reported were due to issues in memory and cognition. Written instructions, detailed assignments, and electronic organizers were discussed as possible solutions to these cognitive barriers. 


\subsubsection{Accommodation strategies suggested by the Job Accommodation Network}

To address the issues of muscle strength, fatigue, and balance issues in this participant's work station, JAN consultants recommended the following possibilities:

- Canes, crutches, and installation of grab bars

- low positioned stools and low task chairs

- an aide/assistant/attendant

- anti-fatigue matting

- ergonomic equipment

- flexible schedule and job restructuring

- periodic rest breaks

- lifting aids

- multi-purpose carts

To help this individual accommodate his memory issues, JAN consultants recommended many of the same accommodations that were previously presented for Participants \#1 and \#2.

\subsection{Case \#4}

The final case is that of a 28-year-old woman who acquired her brain tumor at the age of 13 . She holds a law degree and is employed full-time as a fellowship lawyer at a law firm. In terms of required tasks, this participant's job entails handling cases, communicating with clients, research, and preparing and presenting cases for trial. When asked what symptoms of her brain tumor present functional limitations at work, she noted issues with information processing, taking extra time and effort for research and writing tasks, and difficulty concentrating.

\subsubsection{Accessibility and essential functions}

The participant reported that she is in good shape physically and conveyed that her particular workplace is totally accessible. In the essential functions section of the WES, this participant identified a number of problem areas. These included cognitive abilities such as immediate memory, short-term memory, thought processing, problem solving, and planning. She also identified problems with taskrelated abilities: work-pace/sequencing (too fast); variety of duties (too much); performing under stress/deadlines; little feedback on performance; writing; and remembering. She also indicated difficulty with working conditions and company policies including: noise; always being inside; and a lack of "comp" time.

\subsubsection{Job mastery and job satisfaction}

Across five job mastery categories, this participant checked several problems: "believing that others think I do a good job," "having what I need to do my job (knowledge, tools, supplies, equipment)," "scheduling and planning my work ahead of time," "knowing who to go to if I need help," "understanding company rules and regulations," "having a plan for where I want to be in my job in the future," "understanding what I have to do to get promoted," "knowing what training to complete to improve chances for promotion," "talking with my supervisor about what I need to do to get promoted," "considering what I will do in the future," and "knowing what the opportunities are in this company." With regard to job satisfaction, this participant identified nine work reinforcers as problematic, answering "too little" in response to the following statements: the job gives me a feeling of accomplishment; the job has good working conditions; the job provides an opportunity for advancement; I get recognition for the work I do; my co-workers are easy to make friends with; the company administers its policies fairly; my boss backs up the workers with top management; my boss trains the workers well; and I try out some of my ideas.

\subsubsection{Employee-identified accommodations}

In identifying possible accommodations and resources to conclude the interview, this participant suggested that the difficulties she reported with performing under stress/deadlines could be lessened by communicating with her coworkers and asking for more flexible deadlines or a little "wiggle room" (in her words). Another alternative she identified was asking her supervisors for assistance in prioritizing work tasks and setting deadlines. Supervisors could also provide the employee with additional support in the form of assigning a partner to help her complete the tasks and dividing responsibilities, thereby reducing stress for all parties involved and ensuring that tasks are accomplished in an efficient manner. To address the problems that she experiences with the pace of the work being too fast, the participant explained that she is not sure with whom she can talk about this. After some thought, she supposed that, again, she would need to approach the supervisor and discuss the possibility of more flexible deadlines, prioritization of tasks, and clearer explanations of what needs to be done - in the form of both written directions and/or repeated verbal reminders. It was apparent that this participant's most prominent 
concern was career mastery and knowledge about promotions and how to advance in her career. Again, she speculated that she would need to contact her supervisor on this matter, but she also suggested that it may be a good idea to communicate with her coworkers on this as well to see if they may have any additional insight on how to advance in the legal profession.

\subsubsection{Accommodation strategies suggested by the Job Accommodation Network}

To address the issue of performing under deadlines and stress, JAN consultants suggested the following strategies for her employer to consider:

- provide and allow the use of "apps" to help manage time from the Google Play and iTunes store

- a "color coded" system- color coordination applied to office products and files to help with organization and time management

- timers and watches

- wall calendars and/or planning apps

- provide the employee with clear, detailed written instructions

- "apps" for stress and anxiety

- flexible schedules/employer allow periods of mental rest

- job restructuring/reallocating or redistributing marginal functions of the job

JAN consultants also recommended several strategies to help this participant compensate for her cognitive difficulties, which are essentially the same as those previously presented for Participants \#1 and \#2.

\section{Discussion}

Results indicate that the primary purpose of the study was achieved, namely, the demonstration of a strategy (i.e., the WES) that provides an ecological assessment of the interaction between young employees who are CNS cancer survivors and their immediate work environments. As DillahuntAspillaga et al. (2015) stressed, rehabilitation and psychosocial professionals should place greater emphasis on gathering such information (i.e., personin-situation data) to increase the effectiveness of rehabilitation interventions and the probability of job retention for individuals coping with disabilities. Indeed, the content of the WES is compatible with recommended requirements for vocational evaluation following chronic illness and disability. Stergiou-Kita et al. (2011) recommended that vocational evaluations should address aspects of the physical work environment, workplace culture, and available supports and opportunities. They also emphasized the need for greater involvement of employers in the process of helping individuals with disabilities adapt to the work setting in terms of suggesting both changes in the worker and changes in the work environment. The concrete suggestions provided by JAN pertaining to each of the case studies represent valuable information that employers could use in communicating with their employees. In particular, it is noteworthy that all four participants identified significant problems with cognitive functioning (especially memory), so JAN's recommendations regarding "high-tech" and "lowtech" cognitive supports would seem to be especially germane.

Consistent with the different contexts in which participants worked, a variety of accessibility, essential function, job mastery, and job satisfaction concerns emerged. However, one key similarity among participants is important to note. Participants noted that the most common job retention barriers had to do with the medical effects of cancer, especially cognition, mobility, and physical stamina. The results of the WES interviews suggest that participants generally found the workplace to be accessible. Three of the four participants noted that their workplaces were fully accessible, with one individual noting issues with the company's entrance having limited accessibility due to steps and issues related to lighting.

The impact of the participants' cognitive and physical limitations was evident in the number of essential function difficulties they experienced in their work (i.e., $n=7, n=6, n=3$, and $n=3$ ). Employees who report problems with performing the essential functions of the job are at increased risk for termination and should receive more immediate attention in any "triage" approach to providing on-the-job accommodation assistance. It is important to note that the problems related to meeting the essential functions of the job tended to involve difficulties with memory, physical functioning, and (importantly) meeting the contextual performance demands of the job. Although the cognitive and physical demands of the job can be addressed with specific accommodations, issues related to understanding company policies, receiving feedback on performance, and performing under stress may be more difficult to address and usually require involvement and potential change on the part of the employer (Koch, 2017). 
In addition, some of these supports may need to be provided off site, through the provision of individual vocational/career counseling sessions. One of the strengths of the WES assessment is that these essential function difficulties are specifically described, which serves to guide discussions among rehabilitation and psychosocial counselors, social workers, employers, and employees as well as searches of job accommodation suggestions using resources such as JAN (Ruh et al., 2009).

Job mastery concerns present unique insights into potential problems in job retention. Each of the participants presented different concerns that, in every case, have a direct bearing on their long-term career development and should, therefore, be addressed in rehabilitation follow-along interventions in the workplace. Concerns expressed by participants in this study included believing that others think I do a good job, willing to make changes when necessary, understanding how my job fits into the big picture, knowing who to go to if I need help, understanding company rules and regulations, scheduling and planning my work ahead of time, having what I need to do my job (knowledge, tasks, supplies, and equipment), having a plan for where I want to be in the future, and talking with my supervisor about what I need to do to get promoted.

One should note that the participants' career mastery concerns stem from two sources within the contextual domain of the $\mathrm{IW}^{2} \mathrm{M}$, a) idiosyncratic aspects of a specific work personality and job setting and $b$ ) the more generalized effects of brain tumors on worker/job outcomes. For example, research suggests that, given the late effects related to treatment of childhood brain tumors, individuals are likely to experience difficulties with career identity, work personality, and career readiness (Strauser et al., 2014). Overall lack of work personality could likely explain why participants may be concerned about meeting the contextual demands of the work environment such as scheduling work, talking to the supervisor, and understanding company policies and regulations. Lack of career identity may be associated with an individual's expression of uncertainty regarding having a plan for the future and how the job fits into the big picture. One participant's impression that he did not have what was needed to do a good job suggests some possible difficulties in requesting and receiving job accommodations that would be needed to develop and maintain congruence between the Contextual and Career/Employment domains outlined in the $\mathrm{IW}^{2} \mathrm{M}$. On the other hand, difficulties speaking with a super- visor about job promotions and knowing who to go to for help can be conceptualized as problems encountered by many workers without health-related issues.

Participants in this study reported relatively low levels of job satisfaction. Issues related to not being busy enough, little opportunity for advancement, not achieving a sense of accomplishment, little recognition for work performed, low pay, lack of good working conditions, and lack of co-worker friendships were all significant factors indicating that individuals may not be deriving the positive benefits that ideally attend to labor market participation. This overall lack of employment satisfaction may indicate that participants' employers are not particularly accommodating of their needs. It may also be the case that the lack of satisfaction is related to the perception that participants are "stuck" in their positions with no viable opportunity for career development and advancement. The perceived lack of a viable career development trajectory can be linked to increased stress, depression, anxiety, and an overall decrease in psychological well-being (Strauser, 2013). The importance of this finding is underscored in the IW $^{2} \mathrm{M}$, which suggests that the congruence between the Contextual and Career/Employment Domains leads to increased level of participation and ultimately overall well-being. The accommodations identified as part of the WES interview may be important not only for increasing the individual's ability to meet the demands of his or her current position but also for engaging in career development activities that allow for career advancement. Thus, remediating barriers to job satisfaction, if they exist, is an important step toward increasing the probability of job retention and more importantly increasing the career trajectory among young adult brain tumor survivors. The provision of career development counseling focused on increasing the career trajectory of this particular group should be a major focus of psychosocial treatment programing.

Overall, results of this study underscore the importance of ecological approaches to work assessment (Power, 2011; Wehman, 2013) and the value of an efficient strategy such as the WES to conduct such an assessment. Such an assessment should be comprehensive in nature, providing insights into what Strauser (2013) called for in his tripartite model of work adjustment that includes: a) disabilityrelated barriers to job performance (e.g., physical, cognitive, and psychological symptoms), b) environmental factors (e.g., co-worker attitudes, on-the-job accommodations, employer discrimination), and c) 
interactive influences of the disability and the environment. Rehabilitation professionals should also note that the data collected with the WES were gathered in telephone interviews with participants rather than in site visits, which speaks to the cost effectiveness of the WES (Fakolade et al., 2017).

Data from the WES provide the basis for a discussion among worker, employer, and rehabilitation professional regarding not only threats to job retention but also accommodations needed to reduce or remove those threats. Research on the recommended categories of accommodations that should be considered in discussions to help people with disabilities enhance their job satisfaction and productivity is helpful in this regard. Stergiou-Kitaet al. (2012) asserted that quality vocational assessments and reports should include recommendations regarding "accommodations and or job modifications in relation to work activities, work hours, and graduated return to work schedules; workstation modifications (including reductions to distractions) and adaptive aids/devices and opportunities to apply compensatory strategies; availability of workplace supervision (identification of individuals able to provide ongoing feedback regarding work performance; availability of instrumental support from natural sources in the community such as family, volunteer, or hired support); and availability of vocational rehabilitation supports and services and transportation if the individual is unable to drive" (p. 173). Obviously, consultation regarding the breadth of these accommodations is not a one-time event but rather is needed on an ongoing basis as disability-related symptoms change and as the person ages (Roessler \& Rumrill, 1998).

\section{Limitations}

This investigation had several limitations, the first of which is inherent in using a qualitative case study approach. The sample is limited in size, which affects the diversity of the participants in terms of racialethnic and socio-economic characteristics. Although the study was designed to investigate the fit between employed young adults with brain cancer and their jobs, it did not address issues encountered by young adults with cancer who had not been successful in their career acquisition pursuits (i.e., those who are unemployed). The time frame of the investigation did not allow for follow-up intervention in the workplace to facilitate collaborative accommodation efforts between participants and their supervisors and employers, nor did it permit the interviewer to engage directly with employers and/or rehabilitation professionals on behalf of participants. Future studies should not only investigate the outcomes of this process but also the effects of training employees with brain cancer concerning strategies for independently requesting and implementing the workplace accommodations that they identify through the WES interview and JAN consultation (Roessler \& Rumrill, 2015).

\section{Conclusion}

Individuals coping with the effects of brain cancer experience a variety of cognitive, psychological, and medical symptoms that affect their abilities to succeed in the workplace. Nevertheless, brain cancer survivors such as those who participated in this study have not only a strong commitment to the work role but also the potential to succeed as employees given proper job modifications. For this reason, information pertaining to the nature of the interaction between young adult workers with brain cancer and the work setting (e.g., an ecological assessment) is critical if proper accommodations are to be identified and implemented.

As demonstrated in the four case studies, the Work Experience Survey (WES) is one practical method for identifying barriers that workers with brain cancer are encountering and for initiating discussions about ways to reduce or remove those barriers. Four sections of the WES elaborate on the ways in which cancer influences access to the worksite, performance of essential functions, job mastery, and job satisfaction. If left unaddressed, problems in each of these areas have the potential to disturb worker/job equilibrium and thwart the person's prospects for future career success. In this study, employed brain cancer survivors expressed difficulties in each of these areas, difficulties that relate directly to the multiple cognitive, physical, and psychological symptoms associated with their illnesses. Participants also indicated job accommodations that have increased or would increase their productivity, which provided a basis for accessing other resources such as JAN consultants and its online database. Suggestions from JAN supplement ideas from the worker and the employer and provide information pertaining to the costs and sources of workplace accommodations. Consequently, combining information from the WES and JAN fills an important gap in the assessment of 
the needs of young adults with brain cancer who wish to succeed and advance in their employment.

\section{Author note}

Preparation of this article was partly funded by the United States Department of Labor, Office of Disability Employment Policy in the amount of \$2.5 million under Cooperative Agreement No. OD-32548-18-754-21. This document does not necessarily reflect the views or policies of the U.S. Department of Labor, nor does mention of trade names, commercial products, or organizations imply endorsement by the U.S. Government.

\section{Conflict of interest}

The authors declare that they have no conflict of interest.

\section{Ethical approval}

All procedures performed in studies involving human participants were in accordance with the ethical standards of the institutional and/or national research committee and with the 1964 Helsinki declaration and its later amendments or comparable ethical standards.

\section{Funding}

This study did not use any external or grant related funding.

\section{References}

Allaire, S. H., Li, W., \& LaValley, M. P. (2003). Work barriers experienced and job accommodations used by persons with arthritis and other rheumatic diseases. Rehabilitation Counseling Bulletin, 46(3), 147-156.

Carey, M. E., Barakat, L. P., Foley, B., Gyato, K., \& Phillips, P. C. (2001). Neuropsychological functioning and social functioning of survivors of pediatric brain tumors: Evidence of nonverbal learning disability. Child Neuropsychology, 7(4), 265-272.

Cotton, G. S. (2012). Occupational identity disruption after traumatic brain injury: An approach to occupational therapy evaluation and treatment. Journal of Occupational Therapy in Health Care, 26(4), 270-282.
Crites, J. (1990). Career mastery inventory. Boulder, CO: Crites Career Consultants.

de Boer, A. G., Verbeek, J. H., \& van Dijk, F. J. (2006). Adult survivors of childhood cancer and unemployment: A meta-analysis. Cancer, 107(1), 1-11. https://doi.org/10.1002/ cncr.21974

Dillahunt-Aspillaga, C., Jorgensen-Smith, T., Ehlke, S., Hanson, A., Sosinski, M., \& Gonzalez, C. M. (2015). Disability adjustment and vocational guidance counseling for individuals with traumatic brain injury. Journal of Applied Rehabilitation Counseling, 46(1), 3-13.

Fakolade, A., Finlayson, M., \& Plow, M. (2017). Using telerehabilitation to support people with multiple sclerosis: A qualitative analysis of interactions, processes, and issues across three interventions. British Journal of Occupational Therapy, 80(4), 259-268.

Fossen, A., Abrahamsen, T. C., \& Storm-Mathisen, I. (1998). Psychological outcome in children treated for brain tumor. Pediatric Hematology and Oncology, 15(6), 479-488.

Glaser, A., Abdul Rashid, N., U, C. L., \& Walker, D. A. (1997). School behaviour and health status after central nervous system tumours in childhood. British Journal of Cancer, 76(5), 643650.

Gurney, J. G., Krull, K. R., Kadan-Lottick, N., Nicholson, H. S., Nathan, P. C., Zebrack, B., Tersak, J. M., \& Ness, K. K. (2009). Social outcomes in the childhood cancer survivor study cohort. Journal of Clinical Oncology, 27(14), 2390-2395.

Henrichs, M., \& Schmale, A. (1993). Principles of psychosocial oncology (pp. 159-168). Philadelphia, PA: Clinical Oncology WB Saunders.

Judge, T. A., Erez, A., Bono, J. E., \& Thoresen, C. J. (2003). The core self-evaluations scale: Development of a measure. Personnel Psychology, 56(2), 303-331.

Kirchhoff, A. C., Krull, K. R., Ness, K. K., Armstrong, G. T., Park, E. R., Stovall M., Robison, L. L., \& Leisenring, W. (2011). Physical, mental, and neurocognitive status and employment outcomes in the childhood cancer survivor study cohort. Cancer Epidemiology and Prevention Biomarkers, 20(9), 1838-1849.

Kirchhoff, A. C., Leisenring, W., Krull, K. R., Ness, K. K., Friedman, D. L., Armstrong, G. T., Stovall, M., Park, E. R., Oeffinger, K. C., Hudson, M. M., Robison, L. L., \& Wickizer, T. (2010). Unemployment among adult survivors of childhood cancer: a report from the childhood cancer survivors study. Medical Care, 48(11), 1015-1025.

Koch, L. C., \& Rumrill, P. D. (2017). Rehabilitation counseling and emerging disabilities: Medical, psychosocial, and vocational aspects. Springer Publishing.

Maurice-Stam, H., Grootenhuis, M. A., Caron, H. N., \& Last, B. F. (2007). Course of life of survivors of childhood cancer is related to quality of life in young adulthood. Journal of Psychosocial Oncology, 25(3), 43-58.

Meyer, E. A., \& Kieran, M. W. (2002). Psychological adjustment of 'surgery-only' pediatric neuro-oncology patients: A retrospective analysis. Psycho-Oncology: Journal of the Psychological, Social Behavioral Dimensions of Cancer, 11(1), 74-79.

Michel, G., Rebholz, C. E., von der Weid, N. X., Bergstraesser, E., \& Kuehni, C. E. (2010). Psychological distress in adult survivors of childhood cancer: The Swiss Childhood Cancer Survivor study. Journal of Clinical Oncology, 28(10), 17401748 . 
Mostow, E. N., Byrne, J., Connelly, R. R., \& Mulvihill, J. J. (1991). Quality of life in long-term survivors of CNS tumors of childhood and adolescence. Journal of Clinical Oncology, 9(4), 592-599.

Mulhern, R. K., Carpentieri, S., Shema, S., Stone, P., \& Fairclough, D. (1993). Factors associated with social and behavioral problems among children recently diagnosed with brain tumor. Journal of Pediatric Psychology, 18(3), 339-350.

Ness, K. K., Mertens, A. C., Hudson, M. M., Wall, M. M., Leisenring, W. M., Oeffinger, K. C., Sklar, C. A., Robison, L. L., \& Gurney, J. G. (2005). Limitations on physical performance and daily activities among long-term survivors of childhood cancer. Annals of Internal Medicine, 143(9), 639-647.

Oeffinger, K. C., Mertens, A. C., Sklar, C. A., Kawashima, T., Hudson, M. M., Meadows, A. T., Friedman, D. L., Marina, N., Hobbie, W., Kadan-Lottick, N. S., Schwartz, C. L., Leisenring, W., \& Robinson, L. L. (2006). Chronic health conditions in adult survivors of childhood cancer. New England Journal of Medicine, 355(15), 1572-1582.

Power, P. W. (2011). A guide to career management and programming for adults with disabilities: A 21st century perspective. Pro-Ed.

Recklitis, C. J., Diller, L. R., Li, X., Najita, J., Robison, L. L., \& Zeltzer, L. (2010). Suicide ideation in adult survivors of childhood cancer: A report from the Childhood Cancer Survivor Study. Journal of Clinical Oncology, 28(4), 655-661.

Roessler, R. T., \& Rumrill, P. D. (1998). Reducing workplace barriers to enhance job satisfaction: An important post-employment service for employees with chronic illnesses. Journal of Vocational Rehabilitation, 10(3), 219-229.

Roessler, R., \& Rumrill, P. (2015). Enhancing productivity on your job: The 'win-win' approach to reasonable accommodations. New York, NY: National Multiple Sclerosis Society.

Roessler, R., Reed, C., \& Rumrill, P. (1995). The Work Experience Survey (WES) manual. Arkansas Research \& Training Center in Vocational Rehabilitation.

Ruh, D., Spicer, P., \& Vaughan, K. (2009). Helping veterans with disabilities transition to employment. Journal of Postsecondary Education and Disability, 22(1), 67-74.

Rumrill, P., \& Bellini, J. (2018). Research in rehabilitation counseling (3rd ed.). Charles C. Thomas.

Rumrill, P., Roessler, R., Vierstra, C., Hennessey, M., \& Staples, L. (2004). Workplace barriers and job satisfaction among employed people with multiple sclerosis: An empirical rationale for early intervention. Journal of Vocational Rehabilitation, 20(3), 177-183.

Seaver, E., Geyer, R., Sulzbacher, S., Warner, M., Batzel, L., Milstein, J., \& Berger, M. (1994). Psychosocial adjustment in long-term survivors of childhood medulloblastoma and ependymoma treated with craniospinal irradiation. Pediatric Neurosurgery, 20(4), 248-253.
Stergiou-Kita, M., Dawson, D. R., \& Rappolt, S. G. (2011). An integrated review of the processes and factors relevant to vocational evaluation following traumatic brain injury. Journal of Occupational Rehabilitation, 21(3), 374-394.

Stergiou-Kita, M., Dawson, D., \& Rappolt, S. (2012). Interprofessional clinical practice guideline for vocational evaluation following traumatic brain injury: A systematic and evidence-based approach. Journal of Occupational Rehabilitation, 22(2), 166-181.

Strauser, D. R. (Ed.). (2013). Career development, employment, and disability in rehabilitation: From theory to practice. Springer Publishing Company.

Strauser, D. R., Jones, A., Chiu, C. Y., Tansey, T., \& Chan, F. (2015). Career development of young adult cancer survivors: A conceptual framework. Journal of Vocational Rehabilitation, 42(2). https://doi.org/10.3233/JVR-150733.

Strauser, D. R., Wagner, S., \& Wong, A. W. K. (2012). Enhancing psychosocial outcomes for young adult childhood CNS cancer survivors: Importance of addressing vocational identity and community integration. International Journal of Rehabilitation Research, 35(4), 311-316. https://doi.org/10.1097/MRR.0b013e3283559b4e

Strauser, D., Klosky, J. L., Brinkman, T. M., Wong, A. W., Chan, F., Lanctot, J., Ojha, R. P., Robison, L. L., Hudson, M. M., \& Ness, K. K. (2014). Career readiness in adult survivors of childhood cancer: A report from the St. Jude Lifetime Cohort Study. Journal of Cancer Survivorship, 9(1), 20-29. https://doi.org/10.1007/s11764-014-0380-4

Strauser, D., Wagner, S., Wong, A. W., \& O'Sullivan, D. (2013). Career readiness, developmental work personality and age of onset in young adult central nervous system survivors. Disability and Rehabilitation, 35(7), 543-550. https://doi.org/10.3109/09638288.2012.703754.

Swanson, J. L., \& Schneider, M. (2013). Minnesota theory of work adjustment. In S. Brown \& R. Lent (Eds.), Career development and counseling (2nd ed., pp. 29-54). John Wiley.

Vannatta, K., Gartstein, M. A., Short, A., \& Noll, R. B. (1998). A controlled study of peer relationships of children surviving brain tumors: Teacher, peer, and self ratings. Journal of Pediatric Psychology, 23(5), 279-287.

Wehman, P. (2013). Life beyond the classroom (5th ed.). Paul Brookes Publishing.

Zeltzer, L. K., Recklitis, C., Buchbinder, D., Zebrack, B., Casillas, J., Tsao, J. C., Lu, Q., \& Krull, K. (2009). Psychological status in childhood cancer survivors: A report from the Childhood Cancer Survivor Study. Journal of Clinical Oncology, 27(14), 2396-2404. 